\title{
Variations physiologiques des activités lipasiques et de la lipolyse spontanée dans les laits de vache, de chèvre et de femme : revue bibliographique ${ }^{(1)}$
}

\author{
par \\ Yves CHILLIARD*
}

\section{P L A N}

I. Définitions et position du problème

$1^{\circ}$ Lipases intrinsèques et extrinsèques.

$2^{\circ}$ Lipolyse "induite " et lipolyse "spontanée ».

3o Composants du système lipolytique du lait.

II. Nature et propriétés des activités lipasiques intrinsèques présentes dans le lait

A. Nature des activités lipasiques.

B. RôLE ET MODE D'ACTION DE LA LIPOPROTÉINE-LIPASE DANS

L'ORGANISME ANIMAL :

1. Aspects cellulaires.

$2^{\circ}$ Aspects moléculaires.

C. PRopriÉtÉs DE LA LIPOPROTEINE-LIPASE DU LAIT :

10 Propriétés générales.

* Laboratoire de la Production Laitière, I.N.R.A.-C.R.Z.V. de Theix - 63110 Beaumont.

(1) Texte élargi de la conférence présentée aux Journées du Centre de formation permanente et de perfectionnement des cadres des Industries du lait (C.E.P.I.L.) sur la lipolyse dans le lait et les produits laitiers, les 12 et 13 mars 1980, à l'Institut National Agronomique Paris-Grignon (Centre de Grignon). 
2. Systèmes de mesure in vitro avec des substrats à acides gras à longue chaîne.

30 Systèmes de mesure in vitro avec des substrats à acides gras courts :

a) Tributyrine émulsifiée par agitation.

b) Tributyrine émulsifiée par de la gomme arabique.

\section{Lipase et lipolyse spontanée dans le lait de vache}

A. Composants du système lipolytioue :

$1^{\circ}$ Relation entre l'activité lipasique et la lipolyse spontanée.

2० Etat des globules gras.

3o Localisation de la lipase du lait :

a) Lait natif.

b) Lait refroidi à $4^{\circ} \mathrm{C}$.

$4^{\circ}$ Activateurs de la lipase et/ou de la lipolyse :

a) Polypeptides ou lipoprotéines.

b) Héparinoïdes.

$5^{\circ}$ Inhibiteurs de la lipase et/ou de la lipolyse:

a) Acides gras libres.

b) Autres inhibiteurs.

$6^{\circ}$ Activité lipogénique du lait.

$7^{\circ}$ Influence des cellules somatiques.

$8^{\circ}$ Conclusion.

B. Variations PHysiologiques de L'ACtivité lipasique ET DE LA LIPOLYSE SPONTANÉE DANS LE LAIT DE VACHE :

1. Variations individuelles et à court terme.

2。 Variations au cours du cycle de reproduction :

a) Influence du stade de lactation :

a)1. Activité lipasique.

a)2. Lipolyse spontanée.

b) Influence du cycle œstral et de la gestation.

c) Cas du colostrum.

3o Influence de l'alimentation :

a) Niveau des apports :

a)1. Périodes de sous-alimentation.

a)2. Périodes de réalimentation.

b) Composition de la ration :

b)1. Fourrages verts ou conservés.

b)2. Rapport fourrages/concentrés.

b)3. Taux de protéines.

b)4. Lipides alimentaires :

b)4.1. Acides gras saturés.

b) 4.2. Huiles végétales protégées.

b)4.3. Discussion. 
$4^{\circ}$ Influence des mammites.

5० Conclusion.

\section{Lipase et lipolyse spontanée dans le lait de chèvre}

A. Composants du système lipolytique :

$1^{\circ}$ Relation entre l'activité lipasique et la lipolyse spontanée.

$2^{\circ}$ Etat des globules gras.

$3^{\circ}$ Localisation de la lipase du lait.

$4^{\circ}$ Activateurs de la lipase et/ou de la lipolyse.

$5^{\circ}$ Inhibiteurs de la lipase et/ou de la lipolyse.

$6^{\circ}$ Activité lipogénique du lait.

B. VARIATIONS PHYSIOLOGIQUES DE L'ACTIVITÉ LIPASIQUE ET DE LA LIPOLYSE SPONTANÉE DANS LE LAIT DE CHËVRE :

$1^{\circ}$ Variations individuelles et à court terme.

2. Variations au cours de la lactation.

30 Influence de l'alimentation.

40 Relations entre les activités lipoprotéine-lipasiques du lait, de la mamelle et du tissu adipeux.

\section{Lipases et lipolyse spontanée dans le lait de femme.}

\section{Autres espèces.}

VII. Conclusion.

$$
\text { * }
$$

Le lait est fréquemment stocké au froid pendant 48 ou $72 \mathrm{~h}$ après la traite, avant d'être transformé. Ce stockage à $4^{\circ} \mathrm{C}$ s'accompagne d'une série de modifications, sous l'action de facteurs intrinsèques et/ou extrinsèques, qui peuvent affecter de façon significative la qualité du lait et des produits laitiers. Parmi ces modifications, la lipolyse de la matière grasse se traduit par une libération d'acides gras avec apparition, au-delà de certains seuils, de défauts organoleptiques $[151,61]$.

L'importance technologique pratique de ce phénomène est attestée par les travaux importants qui ont été consacrés à la lipolyse par la Fédération Internationale de Laiterie [92, 93, 94], auxquels le lecteur pourra se référer pour une analyse détaillée des différents aspects de la lipolyse induite et bactérienne dans le lait de vache et les produits laitiers. 
L'objet de la présente revue est, après avoir précisé la nature des différents composants du système lipolytique du lait, de faire le point sur les variations physiologiques de l'activité lipasique intrinsèque, en relation avec les variations de la lipolyse spontanée dans le lait refroidi à $4^{\circ} \mathrm{C}$. Les données relatives à la vache seront en particulier comparées avec celles obtenues récemment chez la chèvre et la femme.

\section{DEFINITIONS ET POSITION DU PROBLEME}

\section{$1^{\circ}$ LIPASES INTRINSÈQUES ET EXTRINSÈQUES}

Lorsque le lait contient moins de $10^{6}$ à $10^{7}$ bactéries par $\mathrm{ml}$, l'action des lipases bactériennes peut être considérée comme négligeable [76]. La lipolyse résulte alors essentiellement de l'action de la lipase (des lipases) intrinsèque(s), sécrétée(s) par la mamelle avec les autres constituants du lait.

\section{$2^{\circ}$ LIPOLYSE « INDUITE 》 ET LIPOLYSE « SPONTANÉE 》}

Le développement de la lipolyse dans le lait fraîchement recueilli dépend en partie des traitements mécaniques et thermiques qui lui ont été appliqués au cours de la traite et après celle-ci. La lipolyse " induite " est généralement considérée comme le résultat d'une agitation mécanique et/ou d'une « activation » thermique [246]. La lipolyse "spontanée " a été définie par l'évolution de la teneur en acides gras libres (AGL) des laits rapidement refroidis et stockés à $4^{\circ} \mathrm{C}$ après la traite [138]. Downey [76] propose d'étendre ce concept à tous les laits n'ayant pas subi d'agitation mécanique particulière, même lorsqu'ils n'ont pas été refroidis rapidement.

La frontière entre lipolyse induite et lipolyse spontanée est mal définie et n'est en fait qu'une question de degré. En effet, le lait recueilli au cours d'une traite manuelle ou mécanique a obligatoirement subi une agitation mécanique au cours de celle-ci. Par ailleurs, le passé thermique du lait interagit fortement avec l'effet des traitements mécaniques sur la lipolyse [121, 97]. Les laits récoltés dans les tanks de ferme présentent donc une lipolyse induite mécaniquement par la traite et l'agitation dans le tank, et thermiquement par les refroidissements et les réchauffements lors des traites successives.

Dans cette revue, le terme de lipolyse spontanée sera utilisé pour des laits individuels, récoltés sans agitation mécanique particulière, refroidis rapidement après la traite et stockés à $4^{\circ} \mathrm{C}$ pendant 24 ou $36 \mathrm{~h}$. La lipolyse est définie, sauf précision dans le texte, comme différence entre la teneur en AGL après $24 \mathrm{~h}$ de stockage et la teneur initiale (post-traite) en AGL. Une revue critique des différentes méthodes des dosages des AGL du lait a été effectuée par KUzDzaLSAvoIE [152]. 


\section{$3^{\circ}$ COMPOSANTS DU SYSTÈmE LIPOLYTIQUE DU LAIT}

Le développement de la lipolyse spontanée résulte de plusieurs composants présents dans le lait :

- les globules gras et leurs caractéristiques (susceptibilité à l'action des lipases);

- la (les) lipase(s) naturelle(s). Son action dépend de sa nature, de la quantité présente dans le lait (1), de sa répartition dans les phases du lait et de la présence d'inhibiteurs ou d'activateurs spécifiques dans celles-ci;

- l'activité lipogénique du lait, (activité de systèmes enzymatiques estérifiant les AGL) qui peut éventuellement freiner l'augmentation de la teneur en AGL;

- les cellules somatiques.

\section{NATURE ET PROPRIETES DES ACTIVITES LIPASIQUES INTRINSEQUES PRESENTES DANS LE LAIT}

\section{A. Nature des activités lipasiques}

La diversité des dénominations employées dans le tableau 1 est due en partie à celle des méthodes employées tant pour la mesure des activités lipasiques (substrats et conditions de milieu) que pour la purification de certaines d'entre elles.

Malgré les nombreux travaux effectués depuis 1920 et surtout 1950 sur le lait de vache, ce n'est que depuis 1975 [93] qu'il est bien établi qu'une seule lipase joue un rôle important dans le lait normal de cette espèce. Cette lipase possède les caractéristiques des lipoprotéines-lipases (LPL) (travaux des équipes d'Olivecrona en Suède, CAStBerg en Norvège [186] et Downey en Irlande) (2).

Ceci semble également valable pour le lait de chèvre $[32,46]$.

Par contre, le lait de femme et de gorille possède, outre la LPL, une autre lipase importante, qui est stimulée par les sels biliaires [119, 120] et n'existe pas chez les primates inférieurs [33] et les autres mammifères.

(1) La lipolyse est mesurée en tant que libération d'acides gras dans le lait "in vivo ", généralement pendant $24 \mathrm{~h}$. L'activité lipasique représente un potentiel de lipolyse. Elle est mesurée in vitro en faisant agir la lipase en très faible quantité (lait dilué...) pendant quelques minutes ou dizaines de minutes sur un substrat souvent différent de la matière grasse du lait et dans des conditions de milieu optimales ( $\mathrm{pH}$, accepteur d'AGL, cofacteurs...). Ce potentiel de lipolyse "in vitro " est toujours très supérieur à la lipolyse proprement dite dans le lait "in vivo".

(2) DoWNEY [75] pense toutefois que cette assertion nécessite des études supplémentaires. Par ailleurs, SHAHANi et al. [226] suggèrent une parenté entre la lipase du lait et la lipase pancréatique bovines. 


\section{TABLEAU 1}

Principales enzymes lipolytiques naturellement présentes dans le lait des différentes espèces



(a), (b), (c), (d) Les activités lipolytiques figurées avec la même lettre sont probablement dues à la même enzyme.

(1) Activité d'environ $5 \mu \mathrm{Eq} \mathrm{AGL} / \mathrm{h} / \mathrm{ml}$.

(2) $80 \mu \mathrm{Eq} \mathrm{AGL} / \mathrm{h} / \mathrm{ml}$.

(3) 500 à $3000 \mu \mathrm{Eq} \mathrm{AGL} / \mathrm{h} / \mathrm{ml}$.

(4) $5 \mu \mathrm{Eq} \mathrm{AGL} / \mathrm{h} / \mathrm{ml}$. Voir le tableau 5 et le texte pour les niveaux d'activité lipasique chez la vache, la chèvre, la bufflonne et la femme. 


\section{B. Rôle et mode d'action de la lipoprotéine-lipase dans l'organisme animal}

\section{$1^{\circ}$ Aspects cellulaires}

La LPL est présente dans les tissus qui utilisent les acides gras des triglycérides sanguins : tissus adipeux, muscles, poumons,

\section{TABLEAU 2}

Quelques facteurs de variation du prélèvement des triglycérides sanguins et/ou de l'activité lipoprotéine-lipasique de différents tissus

\begin{tabular}{|c|c|c|c|c|c|}
\hline \multirow{2}{*}{ Etat physiologique } & \multirow{2}{*}{ Espèce } & \multicolumn{3}{|c|}{ Tissu } & \multirow{2}{*}{ Références } \\
\hline & & $\begin{array}{l}\text { mam- } \\
\text { maire }\end{array}$ & $\begin{array}{l}\text { adi- } \\
\text { peux }\end{array}$ & $\begin{array}{l}\text { mus- } \\
\text { culaire }\end{array}$ & \\
\hline $\begin{array}{l}\text { Restriction de l'apport } \\
\text { énergétique }\end{array}$ & $\begin{array}{l}\text { Rat (1) } \\
\text { Agneau } \\
\text { Bøuf } \\
\text { Chèvre } \\
\text { Brebis }\end{array}$ & 0 & $\begin{array}{l}- \\
- \\
-\end{array}$ & + & $\begin{array}{l}\text { ROBINSON, 1963, } 1970 ; \\
\text { RAULT et al.,1974 } \\
\text { HAUGEBACK et al., } 1974 \\
\text { DIMARCO et al., } 1981 \\
\text { CHILLIARD et al., } 1979 \text { et } \\
\text { non publié } \\
\text { DoIZE et PAQUAY, } 1980\end{array}$ \\
\hline $\begin{array}{l}\text { Début de lactation } \\
\text { (et fin de gestation) }\end{array}$ & $\begin{array}{l}\text { Ratte } \\
\text { Vache } \\
\text { Chèvre } \\
\text { Brebis }\end{array}$ & $\begin{array}{l}+ \\
+ \\
+\end{array}$ & $\begin{array}{l}- \\
-\end{array}$ & 0 & $\begin{array}{l}\text { OTWAY et ROBINSON, 1968; } \\
\text { HAMOSH et al., 1970; } \\
\text { CHILDS et al., } 1981 \\
\text { SHIRLEY et al., 1973 } \\
\text { CHILLIARD et al., 1977, } \\
1978 \text { a, 1978 b et non } \\
\text { publié } \\
\text { VERNON et al., } 1980\end{array}$ \\
\hline $\begin{array}{l}\text { Régime enrichi en } \\
\text { lipides }\end{array}$ & \begin{tabular}{|l} 
Rat \\
\\
Bœuf \\
Vache
\end{tabular} & + & + & + & $\begin{array}{l}\text { WEISENBURG-DELORME et } \\
\text { HARRIS, 1975; } \\
\text { DE GASQUET } \text { et al., } 1977 \text {; } \\
\text { DURAND et PENOT, } 1978 \\
\text { YANG et al., } 1978 \\
\text { STORRY et al., 1974, } 1980\end{array}$ \\
\hline $\begin{array}{l}\text { Régime pauvre en } \\
\text { fibres cellulosiques }\end{array}$ & Vache & - & + & & $\begin{array}{l}\text { BENSON et al., } 1972 \text {; } \\
\text { EMERY, } 1973 \\
\text { ANNISON et al., } 1974 \text {; } \\
\text { JENNY, } 1974\end{array}$ \\
\hline
\end{tabular}

+ , augmente ; 0 , varie peu ; - diminue.

(1) Les mêmes adaptations sont observées lors du stress, de l'effort physique ou de l'adaptation au froid. Dans ce dernier cas, l'activité LPL diminue dans le tissu adipeux blanc et augmente dans le tissu adipeux brun et les muscles (RADOMSKI et OrMe, 1971 ; Goubern et PorTet, 1981). 
mamelle, [revues 149, 211, 212]. Son activité, étroitement liée au prélèvement des triglycérides par ces tissus, est finement régulée, notamment par voie hormonale, en fonction des besoins spécifiques de chaque tissu lorsque varient l'état physiologique et/ou les disponibilités énergétiques de l'animal (tabl. 2).

Il a été montré, dans le cas du tissu adipeux et des muscles, que l'enzyme est synthétisée dans les cellules adipeuses ou musculaires, d'où elle migre vers son site d'action physiologique, l'endothélium des capillaires sanguins, probablement grâce aux glycoprotéines (héparan sulfate) des membranes cellulaires [185]. Il en est probablement de même pour les cellules épithéliales sécrétrices mammaires [57, 59]. L'injection d'héparine se traduit par la libération de LPL dans le sang, probablement par suite d'une liaison électrostatique entre ces deux molécules, en compétition avec la liaison LPL-glycoprotéines des membranes cellulaires [185].

\section{$2^{\circ}$ AsPeCtS MOLÉCULAIRES}

Les triglycérides sanguins circulent principalement dans les lipoprotéines à très basse densité (VLDL) et les chylomicrons. Dans ces particules, les triglycérides (lipides apolaires) ne sont pas exposés à l'interface eau-huile, mais sont enveloppés par une couche de protéines et de phospholipides (lipides polaires), ce qui abaisse fortement la concentration interfaciale en triglycérides et diminue considérablement l'action de la LPL [184]. Celle-ci est en fait permise par la présence de polypeptides " activateurs " (en particulier l'Apoprotéine C-II [156] synthétisés dans le foie et transportés principalement par les lipoprotéines à haute densité (HDL). L'apo C-II est un polypeptide comprenant 78 acides aminés. KINNUNEN et al. [146] suggèrent que son extrémité ayant un radical $\mathrm{NH}_{2}$ se lie aux phospholipides des VLDL. Son extrémité portant un radical $\mathrm{COOH}$ a une forte affinité pour la LPL, ce qui permettrait à l'enzyme de se lier à son substrat triglycéridique localisé au centre des particules lipoprotéiques. Une telle intervention de l'Apo C-II rappelle celle de la colipase dans l'action de la lipase pancréatique au cours de la digestion des lipides dans l'intestin [24]. Toutefois, Bengtsson et Olivecrona [25] proposent, sur la base d'études récentes, que 1'Apo C-II intervient en modifiant l'enzyme et/ou le substrat, sans intervenir de façon décisive dans la liaison enzyme-substrat. Ainsi, la LPL aurait 3 sites impliqués dans son activité : un site actif (hydrolyse), un site de liaison avec le substrat, un site d'interaction avec le polypeptide activateur [27].

Lorsque les conditions nécessaires à l'action de la LPL d'un tissu sur les triglycérides circulants sont réunies, l'enzyme hydrolyse les liaisons esters et les acides gras ainsi libérés peuvent être captés facilement par le tissu (voir Scow et al. [221] pour la description détaillée de ce processus). 
Le mécanisme intime d'action de la LPL n'a pas été étudié chez les ruminants. Bien que ces espèces présentent des particularités dans les concentrations et le turn-over des différentes classes de lipoprotéines, les investigations sur le métabolisme de celles-ci suggèrent que le schéma proposé pour les monogastriques est valable chez les ruminants $[21,29,161,159,193,237,200,236]$.

\section{Propriétés de la LPL du lait}

Les études fondamentales sur les propriétés de la LPL du lait ont surtout été réalisées par OLIVECRONA et al. L'enzyme purifiée à partir du lait de vache est une source abondante et facile à obtenir de LPL et a fréquemment servi de modèle pour des investigations à caractère plus général.

\section{$1^{\circ}$ Propriétés généRALES}

La LPL peut être purifiée par chromatographie d'affinité sur héparine-sépharose. C'est une glycoprotéine, constituée de deux polypeptides ayant un poids moléculaire de 50000 dalton et contenant des glucides (acide sialique notamment) [130]. La LPL du lait de femme a les mêmes caractéristiques et ces deux enzymes ont une parenté immunologique entre elles, ainsi qu'avec la LPL du plasma post-héparine humain [117].

La LPL est fortement thermolabile. Dans le lait par exemple, elle est inactivée en quelques secondes à $72^{\circ} \mathrm{C}$, en quelques minutes à $60^{\circ} \mathrm{C}$, quelques heures à $37^{\circ} \mathrm{C}$ et quelques jours à $5-15^{\circ} \mathrm{C}$, d'où les possibilités de thermisation du lait connues depuis longtemps. Cette inactivation est accentuée par des $\mathrm{pH}$ alcalins ou acides, ainsi que par les rayons ultra-violets [40].

L'enzyme peut hydrolyser plusieurs types de substrats, en particulier les triglycérides composés d'acides gras à courte ou à longue chaîne et les glycérides partiels [87], et les phospholipides [222, 88]. Elle hydrolyse seulement les liaisons ester situées en position externe (sn - 1 et sn -3) sur la molécule de glycérol [181], avec probablement une préférence pour la liaison sn -1 [178]. Par contre, la LPL du lait ne présente pas de spécificité d'acides gras, quels que soient la longueur de chaîne ou le degré d'insaturation [177].

2० Systèmes de mesure in Vitro AVEC DES SUbSTRATS A ACIDES GRAS A LONGUE CHAÎNE

(huile de soja, trioléine,... émulsifiées à l'aide de phospholipides ou de détergents).

\section{Cofacteurs nécessaires :} substrat ; 
- albumine (ou $\mathrm{Ca}^{++}$) pour capter les AGL [223] et lever ainsi l'inhibition des AGL sur la lipase (inhibition due à la formation d'un complexe LPL-AGL [26]) ;

- héparine (polyanions) dans certains cas (levées d'inhibitions, stabilisation de l'enzyme [129];

$-\mathrm{pH}$ optimum $=8$ à 9 .

Inhibiteurs :

- concentration élevée en sels ( $\mathrm{NaCl} 0,5$ à $1,0 \mathrm{M} . .$.$) ;$

- sulfate de protamine (polycations), sels biliaires [149];

- apoprotéines spécifiques (Apo C-III...) [36, 56];

- protéines non spécifiques lorsque la concentration en sels est élevée $[24,131]$.

Deux hypothèses sont avancées pour expliquer l'inhibition de la LPL par le $\mathrm{NaCl}$ :

- les anions $\left(\mathrm{Cl}^{-} \ldots\right)$ interviendraient en compétition avec des résidus à charge négative d'un site actif de la LPL, empêchant ainsi la liaison LPL-Apo C-II et l'action de l'enzyme [95];

- le $\mathrm{NaCl}$ potentialiserait l'effet inhibiteur de certaines protéines sans agir sur la liaison LPL-Apo C-II [24]. Ces protéines inhiberaient l'action de la LPL en s'adsorbant à la surface des particules lipoprotéiques et empêchant la liaison de la LPL avec son substrat triglycéridique. Ce type d'inhibition peut être levé en accroissant la concentration en substrat et/ou en cofacteurs protéiques (compétition pour les sites de liaison).

Quel que soit le mécanisme en cause, le $\mathrm{NaCl}$ (1 M) est efficace pour stopper la lipolyse spontanée dans le lait [23].

30 SYSTÈmES DE MESURE IN VITRO AVEC DES SUBSTRATS A ACIDES GRAS courTs (tributyrine) :

a) Tributyrine émulsifiée par agitation [87] :

- activité optimum en l'absence d'Apo C-II et d'accepteurs d'AGL (cf. solubilité du butyrate) ;

- pas d'inhibition par le $\mathrm{NaCl}$ en période de vitesse initiale;

- enzyme instable, car dénaturée à la surface de l'émulsion, surtout si le $\mathrm{pH}$ est alcalin $(8,6)$, la température élevée $\left(25^{\circ} \mathrm{C}\right)$ et la concentration en $\mathrm{NaCl}$ forte $(0,5$ à $1 \mathrm{M})$.

b) Tributyrine émulsifiée par de la gomme arabique [206]

- avec ce type d'émulsion, l'enzyme est protégée contre l'inactivation dès que la liaison enzyme-substrat est établie; l'enzyme ;

- les pH alcalins et les sels n'ont plus d'effet inactivant 
- l'albumine et d'autres protéines inhibent l'enzyme en s'adsorbant sur le substrat (diminution de la concentration effective en substrat), cette inhibition étant levée par l'Apo C-II qui joue à nouveau un rôle dans l'interaction enzyme-substrat (cf. ci-dessus).

La connaissance des propriétés de la LPL dans de tels systèmes simples et bien contrôlés in vitro peut contribuer à une meilleure compréhension des phénomènes conduisant au développement de la lipolyse. Par ailleurs, il apparaît que les propriétés de l'enzyme sont fonction du type de substrat employé. Ceci explique probablement certaines contradictions apparentes de la littérature dans la caractérisation de l'activité lipasique du lait, et la dualité artificielle qui a longtemps existé entre les activités tributyrinasiques et LPL du lait, qui sont en fait dues à la même enzyme [40].

\section{LIPASE ET LIPOLYSE SPONTANEE DANS LE LAIT DE VACHE}

\section{A. Composants du système lipolytique}

\section{RELATION ENTRE L'ACTIVITÉ LIPASIQUE ET LA LIPOLYSE SPONTANÉE}

Il n'existe généralement pas de corrélation significative entre l'activité lipasique (la quantité de lipase présente) et la lipolyse spontanée du lait de vache $[84,81,43,217]$. Certains auteurs ont toutefois rapporté de bonnes corrélations [115]. En fait, des corrélations de $+0,3$ à $+0,9$ peuvent être observées, selon le type d'expérimentation $[64,65]$.

Ceci signifie que dans certains cas l'activité lipasique est le facteur limitant de la lipolyse (corrélations élevées), alors que dans d'autres cas (fig. 1) ce sont d'autres composants du système lipolytique.

\section{$2^{\circ}$ ETAT DES GLOBULES GRAS}

Les triglycérides du lait sont situés au centre des globules gras et entourés par une double membrane lipoprotéique. La membrane interne, pré-sécrétoire, est probablement constituée d'une couche de phospholipides et de protéines, présente autour des globules gras dès leur formation dans les cellules sécrétrices mammaires. La membrane externe enveloppe les globules gras au cours du processus de sécrétion et proviendrait de la membrane plasmique des cellules sécrétrices et/ou de vésicules golgiennes fusionnant avec celle-ci. La membrane des globules gras présente en outre d'importants réarrangements structuraux et des échanges avec la phase aqueuse du lait, dès que ceux-ci sont sécrétés dans les alvéoles mammaires. (Voir par exemple les revues $[195,143,144,179,8,194,261,199,257])$. 


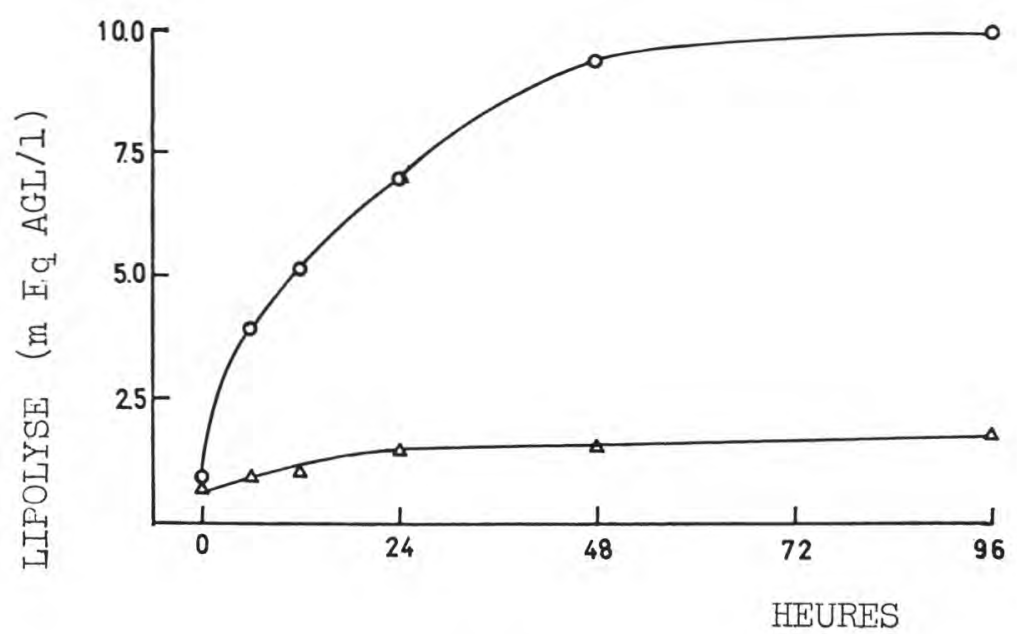

fig. 1

Evolution de la teneur en acides gras libres de deux laits de vache stockés à $4^{\circ} \mathrm{C}$ et ayant la même activité lipoprotéine-lipasique (d'après CASTBERg et SolbERG, 1974 [43]).

Il existe donc une double barrière à la lipolyse, et celle-ci ne peut se dérouler que si la lipase (et son cofacteur) peuvent venir au contact de l'interface eau-huile du substrat [184]. Les globules gras du lait natif séjournant dans la mamelle semblent donc être un très mauvais substrat pour la lipase du lait, comme le suggèrent les très faibles teneurs en AGL du lait normal fraîchement sécrété [122, 217]. Il semble que la lipolyse ne puisse se développer que si elle est initiée par une détérioration " minimum » de la membrane des globules gras (du fait de l'agitation mécanique survenant inévitablement au cours de la traite) et/ou par la présence d'activateurs (voir ci-dessous).

Les caractéristiques des globules gras et de leurs membranes dépendent à la fois de facteurs intrinsèques et de facteurs extrinsèques au cours de la récolte et du traitement du lait. Les facteurs liés à l'animal (race, stade de lactation, régime,...) sont encore mal connus, en particulier en ce qui concerne leurs effets sur la lipolyse [9].

L'influence des facteurs extrinsèques est un peu mieux connue. La membrane des globules gras peut être endommagée par leur contact avec des bulles d'air ou directement par les forces mécaniques provoquées par l'agitation, ainsi que par le refroidissement du lait, qui entraînent la perte de substances membranaires et la cristallisation de la matière grasse. Ces altérations des globules gras 
peuvent aller jusqu'à la formation de matière grasse « libre ». Ceci reflète en fait l'apparition de nouvelles particules grasses recouvertes de protéines sériques, formant une « membrane » qui ne protège plus aussi efficacement la matière grasse contre l'action de la lipase [257].

\section{$3^{\circ}$ LOCALISATION DE LA LIPASE DU LAIT}

\section{a) Lait natif}

La lipase du lait natif semble se trouver exclusivement [79] ou en majeure partie [258] dans le lait écrémé. La membrane des globules gras ne contient pas ou très peu de lipase $[74,179,91]$. La fraction membranaire du lait écrémé semble toutefois posséder une activité lipolytique [244].

La lipase (LPL) du lait écrémé est localisée pour 60 à 90 p. 100 dans les micelles de caséine $[138,77,37,214,218]$, en équilibre avec la lipase liée aux caséines solubles. L'enzyme serait surtout liée aux caséines-K, riches en acide sialique [264, 99]. Les liaisons avec ces glycomacropeptides sont probablement de type électrostatique à l'interface micelle-sérum [79]. Des liaisons plus étroites existeraient avec certaines submicelles de caséine [214].

La LPL peut migrer in vitro de la phase caséique vers la phase sérique sous l'effet du $\mathrm{NaCl}(0,75 \mathrm{M})$ ou de l'héparine $(5 \mathrm{mg} / \mathrm{l})$ [126]. L'héparine agit probablement en entrant en compétition avec les sites de liaison sur les glycoprotéines ([79], cf. §-II B1), alors que le $\mathrm{NaCl}$ permettrait aussi la solubilisation d'une partie des caséines [214].

La partition de la LPL entre les phases caséiques et sérique du lait semble jouer un rôle dans le développement de la lipolyse spontanée. Ainsi, SALIH et ANDERSON $[215,218]$ observent que les laits qui présentent des teneurs élevées en AGL initiaux ont un pourcentage plus élevé de lipase dans le sérum.

b) Lait refroidi à $4^{\circ} \mathrm{C}$

Le refroidissement et le stockage du lait au froid après la traite semblent favoriser le développement de la lipolyse, bien que les résultats rapportés dans la littérature soient parfois difficiles à interpréter (revue [97]).

Cet effet du refroidissement pourrait résulter en partie d'une redistribution de la lipase dans les différentes phases du lait :

- dissociation du complexe caséine-lipase [77];

- solubilisation d'une partie des micelles de caséine [254, 213, 2].

- adsorption de la lipase du sérum sur les globules gras [145, 246] probablement par suite de l'altération de la membrane des globules gras [258]. 
TABLEAU 3

Activation de la lipolyse du lait de vache par addition de sérum sanguin (d'après JeLlema, 1975)

\begin{tabular}{|c|c|c|c|c|}
\hline \multirow{2}{*}{ Lait } & \multicolumn{4}{|c|}{ Sérum sanguin bovin ajouté (p. 100) } \\
\hline & 0 & 0,5 & 2 & 5 \\
\hline Vache I & $0,97(1)$ & & & 5,30 \\
\hline Vache II & 0,63 & & & 4,29 \\
\hline Vache III & 0,60 & & & 2,17 \\
\hline Troupeau A & 0,43 & 0,49 & 1,93 & 3,30 \\
\hline Troupeau B & 0,67 & 0,70 & 1,62 & 2,31 \\
\hline
\end{tabular}

En conclusion, la lipase du lait natif normal n'agit pas sur la matière grasse du lait car elle en est séparée par la membrane des globules gras et d'autre part par sa propre localisation dans la phase aqueuse, caséique principalement. Le refroidissement du lait, qui entraîne une altération de la membrane et une redistribution de la lipase en direction de la phase grasse, crée des conditions favorables à la lipolyse. Cet effet varie en fait avec les propriétés intrinsèques des laits individuels. Ainsi, le pourcentage de lipase dans la crème $(5-10$ p. 100 vs 30 p. 100$)$ et dans le matériel membranaire de la fraction grasse (1-2 p. 100 vs $4-7$ p. 100) est plus faible dans les laits refroidis présentant une faible lipolyse, que dans ceux qui lipolysent spontanément $[246,40]$. Cette redistribution de la lipase vers la phase grasse est de plus largement influencée par les facteurs technologiques (vitesse de refroidissement, agitation,...) [66].

$4^{\circ}$ Activateurs DE LA LiPASE ET/OU DE LA LiPOLYSE

a) Polypeptides ou lipoprotéines

L'addition de sérum sanguin au lait normal provoque un accroissement important de la lipolyse spontanée [43, tabl. 3]. Cette activation résulte surtout de la fraction HDL du sérum [132] qui est riche en Apo C. Il est donc possible de penser que les apoprotéines C interviennent, comme dans le cas des lipoprotéines du sang (cf. \&-II B2) pour créer des conditions favorables à l'action de la LPL à la surface des globules gras du lait. Toutefois, CLEGg [58] a observé récemment que les Apo $\mathrm{C}$ délipidées ne suffisent pas à activer la 
lipolyse spontanée du lait, mais qu'elles doivent être associées à des lipides. Il semble donc que seules les lipoprotéines natives (HDL probablement) aient ce pouvoir activateur dans le lait entier, alors que l'Apo C-II et l'Apo C-I suffisent à stimuler fortement l'action de la LPL du lait sur un substrat artificiel, in vitro $[189,56]$.

Ces effets spectaculaires d'apports exogènes (in vitro) d'activateurs d'origine sanguine ont conduit à rechercher si les laits individuels contiennent de tels activateurs, en particulier lorsque ces laits lipolysent spontanément. En effet, la lipolyse spontanée présente de nombreuses variations liées à l'animal (cf. ci-dessous) dont l'origine pourrait être liée au métabolisme de celui-ci. Or, il est bien connu que certaines protéines sanguines peuvent franchir les barrières mammaires et «filtrer » dans le lait [209, 197].

Des arguments en faveur de cette hypothèse ont été fournis par des études récentes. Ainsi, DrIEssen et STADHouders [81] ont montré que les laits spontanément actifs contiennent un activateur thermostable dans la phase aqueuse, qui semble abaisser le $\mathrm{pH}$ optimum de la lipase (fig. 2), et serait constitué de phospholipides et de protéines. CASTBerg et Solberg [43] ont montré, quant à eux, que le lait contient des lipoprotéines immunologiquement voisines des HDL sanguines qui activent aussi bien l'activité de la LPL que la lipolyse spontanée. ANDERSON [5] a mis au point une méthode immuno-enzymologique (antisérum anti-HDL) permettant de mesurer la concentration relative en activateur dans le lait. La quantité d'activateur est généralement plus élevée dans les laits qui lipolysent et sa répartition dans les phases grasse, aqueuse et caséique varie d'une vache à l'autre.

\section{b) Héparinoüdes}

Les héparinoïdes jouent un grand rôle dans le fonctionnement des LPL in vivo et in vitro (cf. § II B 1 et C2). Par ailleurs, des fractions de lait de vache riches en LPL contiennent aussi de l'héparan sulfate [187] et les glycoprotéines jouent un rôle important dans la structure des micelles de caséine ainsi que dans la liaison LPLcaséines (cf. § III A 3 a).

L'addition d'héparine dans le lait de vache provoque une stimulation de la lipolyse spontanée (fig. 3; Selselet-Attou, Chilliard, Bas et MoRAND-FEHR, non publié), probablement en détachant de manière compétitive la LPL de sites de liaison sur la caséine et/ou en stabilisant l'enzyme. L'effet additif des apports de sérum et d'héparine (fig. 3) résulte vraisemblablement du fait que ces deux activateurs agissent à des niveaux différents dans le système (globules gras et caséines, respectivement).

Des études plus poussées sur la présence d'héparinoïdes endogènes dans le lait, leurs facteurs de variation et leur influence éventuelle sur la lipolyse restent toutefois à effectuer. 


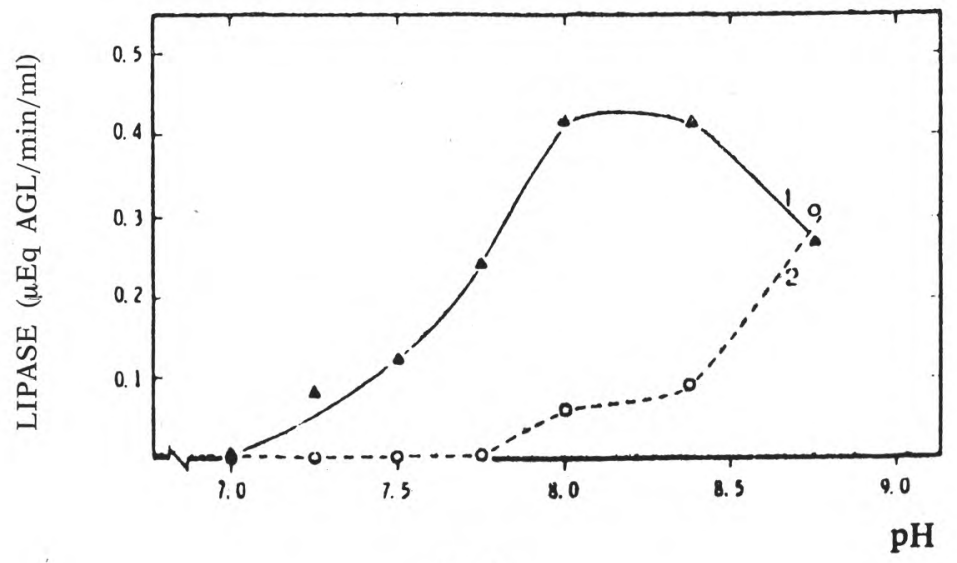

fig. 2

Activité lipolytique d'un lait écrémé provenant d'un lait de vache rancissant spontanément (d'après DRIESSEN et STADHOUDERS, 1975 [82]).

Substrats : Globules gras suspendus dans du lait écrémé provenant : 1. d'un lait rancissant spontanément, pasteurisé, 2. d'un lait normal, pasteurisé.

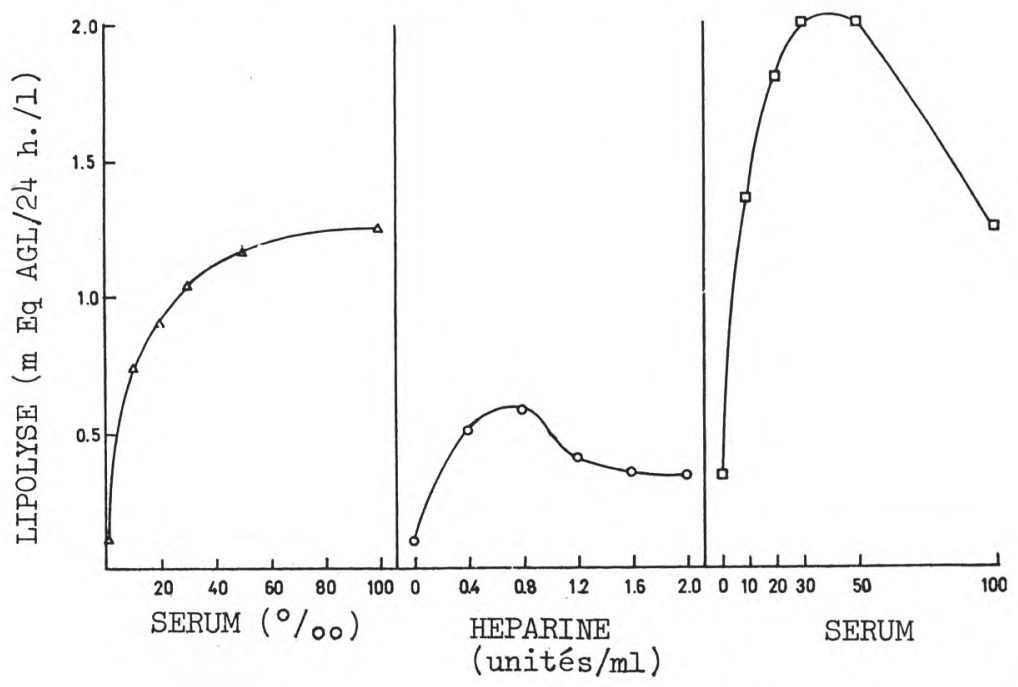

$201.61 .20 .8 \quad Q 4$ 0

HEPARINE

fig. 3

Effet du sérum sanguin et de l'héparine sur la lipolyse du lait de vache stocké à $4^{\circ} \mathrm{C}$ (d'après CASTBERg et SolbERG, 1974 [43]). 
$5^{\circ}$ INHIBITEURS DE LA LIPASE ET/OU DE LA LIPOLYSE

a) Acides gras libres

La LPL est très sensible à l'inhibition par le produit de son action, les acides gras libres à longue chaîne (cf. § II C 2). Lorsque le lait n'est pas agité, les AGL tendent à s'accumuler à la surface des globules gras et la lipolyse plafonne [76].

Les substances qui peuvent lier les acides gras, telles que les albumines ou les ions $\mathrm{Ca}^{++}$, permettent de lever l'effet inhibiteur des AGL sur la LPL. Il est donc possible que les teneurs du lait en ces substances puissent intervenir dans le développement de la lipolyse, bien qu'aucune étude n'ait été consacrée à cet aspect jusqu'ici.

\section{b) Autres inhibiteurs}

Dès 1942, TARASSUK et HENDERSON [247] avaient observé que les laits normaux inhibent la lipolyse dans les laits spontanément actifs, d'où l'hypothèse que les premiers puissent contenir un inhibiteur de la lipase ou de la lipolyse. Ceci est extrêmement attractif d'un point de vue pratique, puisque de nature à limiter fortement la lipolyse spontanée des laits de mélange.

L'existence probable d'un facteur inhibiteur de la lipolyse a été confirmée par les résultats de HaRPer et al. [112] et de DeETH et FITZ-GÉRALD [64], (fig. 4). Ce facteur serait thermostable, dialysable et situé dans la phase aqueuse des laits normaux, mais aussi dans les laits spontanément actifs. Récemment, ANDERson [6] a montré une action inhibitrice de la fraction 3 des protéoses-peptones du lait. Cette fraction est une glycoprotéine qui provient probablement de la désagrégation de la membrane des globules gras; elle n'inhibe pas directement la LPL et agirait plutôt au niveau des globules gras (en accord avec les hypothèses de DeEth et Fitz-Gérald [64] et Clegg [58]). Par ailleurs, SALIH et ANDERson [215, 216] rapportent la présence d'un facteur thermolabile et dialysable, localisé dans le sérum du lait, qui réduirait la stabilité de la LPL à $20^{\circ} \mathrm{C}$, de façon variable selon les vaches étudiées. L'Apo A-I du sang pourrait avoir un effet inhibiteur sur la lipolyse [58], si elle passait dans le lait.

Outre l'existence éventuelle de facteurs pouvant inhiber spécifiquement la lipolyse, SHAHANI et CHANDAN [225] ont rapporté que certaines protéines constitutives du lait ont une action inhibitrice sur la lipase, ce qui est à rapprocher des résultats de l'équipe d'OLIVECRONA (cf. § II C 2-3) sur l'inhibition non spécifique de la LPL purifiée, par diverses protéines. Par ailleurs, le $\mathrm{pH}$ du lait $(6,5$ à 7,2$)$ n'est pas optimum pour la lipase et joue probablement un rôle dans le phénomène $[64,82,11]$.

\section{$6^{\circ}$ Activité LIPOgÉNIQUE DU LAIT}

Plusieurs études effectuées sur le lait de vache suggèrent que la sécrétion lactée s'accompagne du passage dans le lait de fragments 


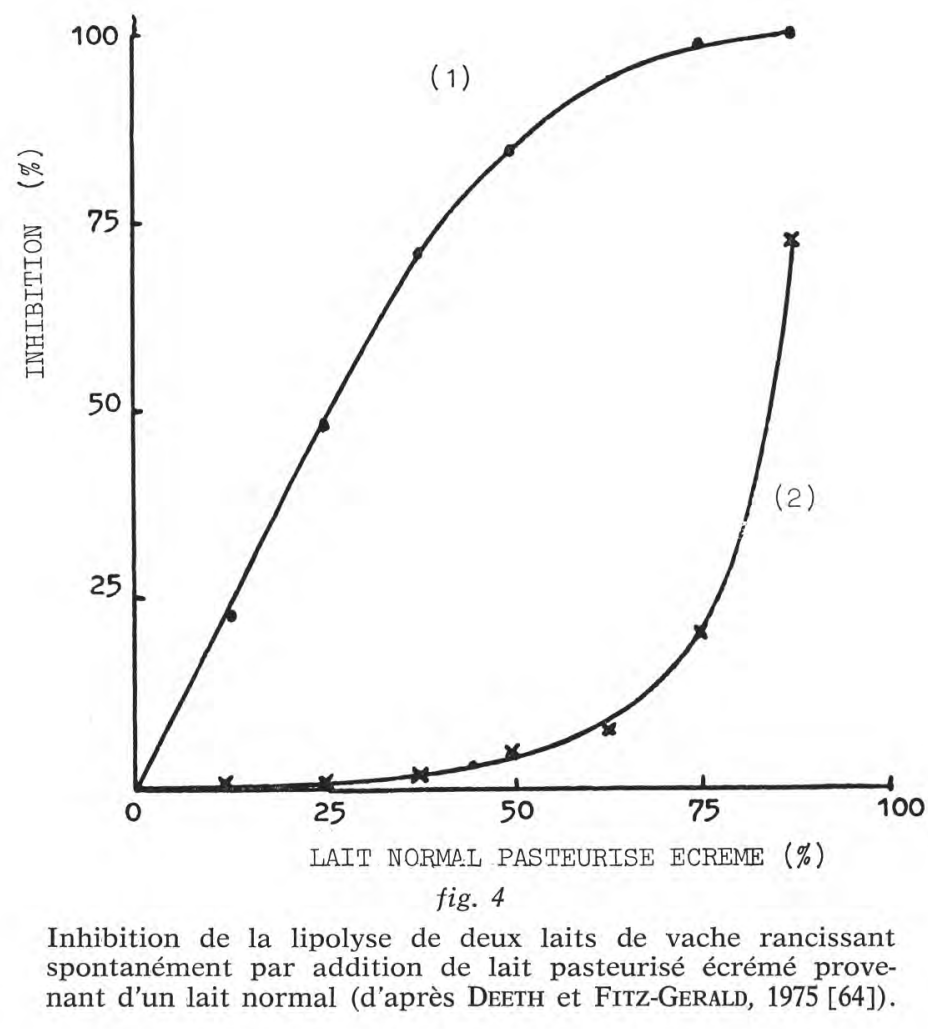

de cytoplasme des cellules sécrétrices [262, 35]. Ceci explique probablement que le lait natif présente notamment une activité de synthèse de glycérides [171] (1).

Il est donc probable que la concentration en AGL du lait résulte d'un équilibre entre lipolyse et lipogénèse [166]. Les variations de cette activité lipogénique, liées à l'animal et aux traitements subis par le lait, sont encore très peu connues.

Il est possible que la présence d'AGL dans le lait normal frâ̂chement sécrété (AGL « initiaux 》) reflète plutôt une synthèse incomplète des triglycérides par le tissu mammaire qu'un développement pré-sécrétoire de la lipolyse [152]. L'estérification de ces AGL par

(1) On sait, par ailleurs, que certaines lipases catalysent à des degrés divers l'estérification des AGL, en tant que réaction inverse de l'hydrolyse des triglycérides et qu'il peut en résulter des modifications de la cinétique de celle-ci [183]. 
les systèmes enzymatiques du lait frais devrait alors être considérée comme une poursuite de la lipogénèse mammaire, pouvant masquer dans une certaine mesure le développement de la lipolyse. Dans cette hypothèse, la seule mesure des AGL " initiaux " ne pourrait pas être considérée comme un indicateur fiable de la lipolyse spontanée, et ceux-ci sont d'ailleurs généralement très peu variables [133].

\section{7\% INFLUENCE DES CELlules SOMATiQues}

Le lait contient des cellules somatiques, constituées en majeure partie de leucocytes d'origine sanguine et lymphatique [191, 157].

Un certain nombre de facteurs physiologiques (stade de lactation), pathologiques (mammites) et technologiques (traite) s'accompagnent de variations du nombre de cellules somatiques dans le lait [172] et de la lipolyse. Ainsi, la lipolyse est en moyenne plus faible dans les laits contenant moins de 300000 cellules/ml [132] et il existe souvent une corrélation positive entre les deux paramètres [227, 96, $140]$.

La question d'un rôle propre des cellules somatiques dans la lipolyse est posée depuis que GafFney et HARPer [104] ont mis en évidence la présence d'une lipase du type carboxyl-estérase $[4,63]$ dans ce type de cellules. Les travaux récents de SALIH et ANDERSON [218] et de JuRczaK et Sciubiz [140] suggèrent que les cellules somatiques jouent effectivement un rôle dans la lipolyse, soit par leur action protéolytique sur la membrane des globules gras et/ou les caséines (libération de la LPL). Ceci n'a toutefois pas été confirmé par LEE et al. [157]. Il faut par ailleurs remarquer que les laits riches en cellules somatiques sont aussi enrichis en éléments d'origine sanguine (protéines, minéraux) qui pourraient modifier la lipolyse. Inversement, les leucocytes pourraient avoir une activité de synthèse de glycérides [167] et ralentir ainsi la lipolyse apparente.

\section{$8^{\circ}$ CONCLUSION}

De nombreux composants du lait interagissent pour déterminer le niveau de lipolyse spontanée ou induite d'un lait individuel ou de mélange. Outre la quantité de lipase présente, les facteurs qui facilitent les interactions entre la matière grasse et la lipase se traduisent par un accroissement de la lipolyse et inversement.

Les études sur l'intégrité de la membrane des globules gras d'une part, sur les activateurs et les inhibiteurs de la lipolyse, leur origine et leur mode d'action d'autre part, ne font que commencer mais devraient permettre des progrès décisifs dans la compréhension des mécanismes de la lipolyse et la maîtrise de celle-ci. Il est aussi nécessaire, dans ce but, de connaître les variations physiologiques (liées à l'animal) de ces phénomènes. 


\section{B. Variations physiologiques de l'activité lipasique et de la lipolyse spontanée dans le lait de vache}

Alors que la lipolyse induite résulte de l'interaction du potentiel lipolytique du lait et des traitements qui lui ont été appliqués, la lipolyse spontanée reflète plus directement les facteurs de variation physiologiques, liés à l'animal, de ce potentiel lipolytique.

\section{$1^{\circ}$ VARIATIONS INDIVIDUELLES ET A COURT TERME}

Tous les auteurs soulignent la très grande variabilité de l'activité lipasique et de la lipolyse spontanée, selon les individus étudiés, et d'un jour à l'autre ou d'un quartier à l'autre pour la même vache (revue [133]). Des coefficients de variation de 50 à 100 p. 100 sont couramment rencontrés. Ceci suggère que la sécrétion de la lipase et/ou des composants du système lipolytique puisse être en partie sujette à des variations aléatoires. Toutefois, la propension à la lipolyse du lait de certains animaux est répétable au cours des lactations successives [155].

Il ne semble pas y avoir d'effet " race » important sur ces deux paramètres (voir par exemple [173, 122, 210, 98, 165]. Un effet génétique intrarace a toutefois été suggéré (revue [65]).

La lipolyse est plus élevée dans le lait du soir que dans celui du matin [137]. Cet effet s'explique par les différences dans les intervalles entre traites [242], le lait du soir étant produit en plus faible quantité et avec un taux butyreux plus élevé.

THomas et al. [251] ont rapporté des teneurs en AGL dans le lait natif (AGL initiaux) plus élevées en début qu'en fin de traite, mais ce résultat (1) n'a pas été confirmé par ERMose et Pedersen [90]. La lipolyse spontanée semble être quand à elle plus élevée dans le lait de fin de traite [242] ; toutefois, LuthaLA et ANTILA [165] trouvent plus de lipase dans le lait de début de traite, alors que Forster et al. [98] n'enregistrent pas de variations de l'activité tributyrinasique. D'autres facteurs tels que la taille des globules gras pourraient aussi intervenir.

2. Variations aU COURS DU CYCLE DE REPRODUCTION

a) Influence du stade de lactation

\section{a)1. Activité lipasique}

L'activité tributyrinasique ou LPL du lait post-colostral est faible ou moyenne en début de lactation et diminue fréquemment en fin de lactation [173, 84, 98, 37, 43] (fig. 5). Toutefois, Homer et VIR-

(1) Le résultat enregistré par ces auteurs pourrait provenir du fait qu'ils expriment la teneur en AGL par rapport à la matière grasse, puisque le taux butyreux augmente au cours de la traite. 


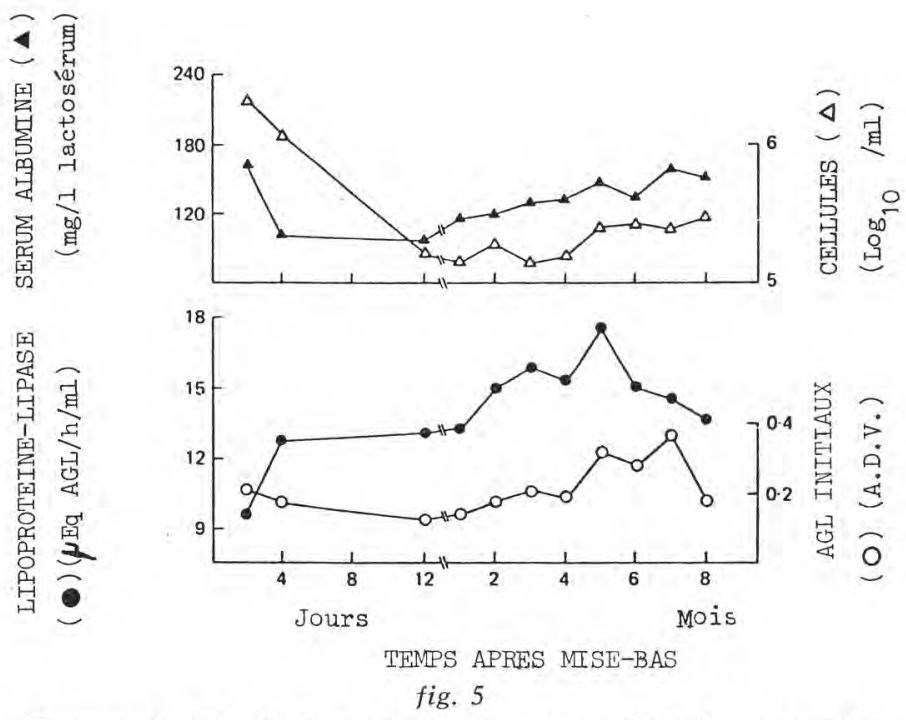

Teneurs du lait de douze vaches en sérum albumine, en cellules somatiques, en lipoprotéine-lipase et en acides gras libres au cours de la lactation (d'après SALIH et ANDERSON, 1979 a [217]). A.D.V. $=\mathrm{m} \mathrm{Eq} \mathrm{AGL/100} \mathrm{g} \mathrm{matières} \mathrm{grasses.}$

tanen [125], Luthala et Antila [165] et Hemingway et al. [115] n'ont pas observé de variations de l'activité lipasique au cours de la lactation et Kogev et Ratchev [148] signalent une forte augmentation de l'activité lipolytique (?) après $270 \mathrm{j}$ de lactation.

\section{a)2. Lipolyse spontanée}

La lipolyse spontanée et la teneur en AGL initiaux sont généralement faibles au début de la lactation et élevées après le $6^{\mathrm{e}}$ mois de lactation (voir par exemple $[123,100,137,155,248,188,65,208$, 133] (fig. 6). Plusieurs auteurs n'ont toutefois pas observé systématiquement ce type de variation $[122,210,84,107,116,115,43]$ (fig. 5).

Bien qu'ayant une faible activité lipasique, les laits de fin de lactation semblent particulièrement susceptibles au développement de la lipolyse. D'autres constituants du système lipolytique pourraient en être la cause, bien que des relations de cause à effet n'aient pas encore été démontrées.

Ainsi, la taille des globules gras est minimale [38] et le taux butyreux s'élève fortement en fin de lactation, ce qui pourrait favoriser l'adsorbtion de la lipase sur la crème [258]; une filtration accrue de composés sanguins activateurs et une augmentation du nombre de cellules somatiques $[220,233,30$, (fig. 5) $]$ pourraient aussi se produire à cette période, ainsi qu'une élévation du taux de $\mathrm{NaCl}$ 


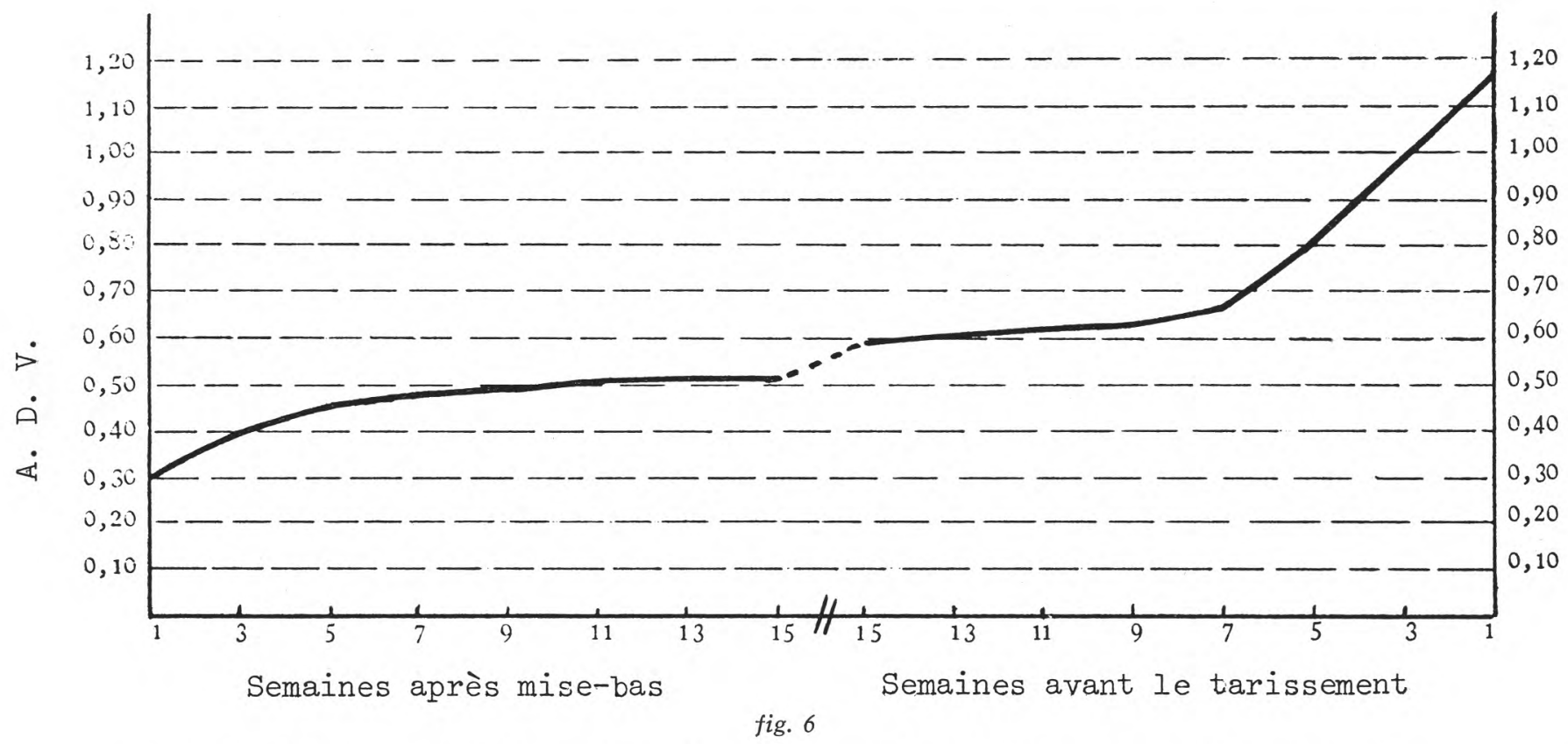

Evolution de la teneur en acides gras libres du lait au cours de la lactation de cinquante-quatre vaches (d'après Menger, 1975 [174]). A.D.V. $=\mathrm{m} \mathrm{Eq} \mathrm{AGL/100} \mathrm{g} \mathrm{matières} \mathrm{grasses}$ 
[22] qui pourrait agir sur la liaison de la lipase avec les micelles de caséine. On a de plus observé une augmentation des caséines solubles en fin de lactation [78] et la composition en caséines du lait pourrait varier avec le stade de lactation [20].

L'influence du stade de lactation est en outre fréquemment mesurée en interaction avec d'autres facteurs, tels que l'alimentation, la saison, le stade de gestation et le niveau de production. Selon JELLEMA [132], le niveau de production serait un facteur plus important que le stade de lactation, la lipolyse augmentant fortement lorsque la production laitière devient inférieure à $3 \mathrm{~kg}$ par jour. Dans l'étude de Castberg et Solberg [43], les lipolyses supérieures à 1,5 $\mathrm{mEq} / 1 / 24 \mathrm{~h}$ ne sont observées que chez les vaches produisant moins de $12 \mathrm{~kg}$ de lait par jour. L'influence de ces deux facteurs (stade de lactation et niveau de production) a été confirmée sur 450 vaches par HunTER et al. [127] mais ces auteurs soulignent que ceux-ci n'expliquent que 6 p. 100 de la variabilité de la lipolyse des laits individuels. L'influence du niveau de production sur les composants du système lipolytique est mal connue. La relation inverse entre lipolyse et niveau de production pourrait résulter en partie d'une forte activité lipogénique du lait (diminution des AGL dans les heures qui suivent la traite) chez les animaux fort producteurs (MAHIEU, 1981, communication personnelle) ? Bien que certaines expériences aient suggéré une relation entre l'état corporel de l'animal et le niveau de lipolyse dans le lait, celle-ci n'a pas été confirmée dans d'autres études [188].

L'absence de corrélation globale entre lipolyse et activité lipasique (cf. § III A 1) ne doit toutefois pas faire sous-estimer le rôle joué par celle-ci. Ainsi, DeETH et Fitz-GÉRALD [64] rapportent qu'une lipolyse spontanée importante en fin de lactation se développe essentiellement chez les animaux présentant une forte activité lipasique au cours de l'ensemble de la lactation. Réciproquement, en début de lactation, l'activité lipasique est faible et bien corrélée avec la lipolyse spontanée $[84,217]$, probablement parce qu'elle en constitue le facteur limitant.

b) Influence du cycle cestral et de la gestation

L'activité lipasique du lait (et du sang) augmente juste avant l'œestrus [145, 121, 259]. Cette augmentation est probablement en relation avec celle de la lipolyse dans les jours qui suivent, bien que de façon faible et variable [121, 100].

L'influence du cycle œstral est vraisemblablement sous dépendance hormonale. En effet, des injections d'cestrogènes et de progestérone se traduisent par un accroissement de l'activité lipasique, en particulier dans la phase grasse du lait [18]. Il faut toutefois noter que ce traitement s'était accompagné d'une forte chute de production laitière. Par ailleurs, avec des traitements hormonaux à base d'œstrogènes (ou dans le cas de maladies ovariennes) on observe des augmentations de la lipolyse spontanée $[121,142,18]$; bien que de manière variable $[100,164]$. CASTBERg et Solberg [43] suggèrent 
que cet effet des œstrogènes puisse lui-même résulter de variations dans la quantité d'héparinoïdes présents dans le lait (cf. § III A 4 b). En effet, PuRnell et Combs [201] ont rapporté que l'activité des cellules productrices d'héparinoïdes dans la glande mammaire de hamster était maximale au moment de l'œstrus. Par ailleurs, la teneur en matière sèche du lait, et en particulier en $\mathrm{NaCl}$, est augmentée par des injections d'œstrogènes [164].

L'élévation des œstrogènes pendant la deuxième partie de la gestation $[69,250]$ peut-elle expliquer en partie l'augmentation de la lipolyse en fin de lactation? Il ne semble pas car l'augmentation des taux d'œstrogènes circulants intervient surtout pendant la période sèche (semaines précédant la mise-bas). D'autre part, les différents auteurs qui ont étudié ce facteur n'ont pas observé d'influence spécifique du stade de gestation sur la lipolyse [122, 100, 43$]$.

\section{c) Cas du colostrum}

Le colostrum présente une activité LPL de faible niveau dès le premier jour de lactation [37, 217]. Toutefois DRIESSEN [80] n'observe pas d'activité LPL dans le lait de vache avant le troisième jour de lactation.

Ces activités LPL réduites expliquent probablement les faibles niveaux de lipolyse observés dans le colostrum, bien que cette sécrétion soit riche en composés d'origine sanguine et en cellules somatiques [217].

Le colostrum présente par ailleurs des activités estérasiques élevées [98] pouvant provenir du sang [256] ou des cellules somatiques [63]. En outre, MatTick et KaY [173] et Singh et Ganguli [232] enregistrent de fortes activités tributyrinasique (1) et lipasique dans le colostrum. DRIESSEN [80] souligne l'existence dans cette sécrétion d'une lipase n'ayant pas les propriétés de la LPL (non stimulée par le sérum sanguin, stable à $\mathrm{pH} 4,6$ ). L'origine, la nature et le rôle physiologique de cette (ces) lipase(s) sont encore inconnus.

\section{INFLUENCE DE L'ALIMENTATION}

\section{a) Niveau des apports}

Bien que l'on fasse souvent état dans la littérature de l'influence de l'apport énergétique sur la lipolyse, ce facteur de variation n'a que rarement été séparé des autres constituants de la ration et les données disponibles concernent le plus souvent l'effet du niveau alimentaire global.

(1) Ce résultat pourrait toutefois refléter une interférence de l'activité cholinestérasique du colostrum [98]. 




fig. 7

Influence d'un supplément d'aliment concentré sur la lipolyse du lait (d'après StoBвS et al., 1973 [239]). Deux lots de six vaches en fin de lactation, sur une pâture de mauvaise qualité, reçoivent $(\bullet, \mathbf{\Delta})$ ou non $(0, \triangle)$ du concentré. La teneur en AGL est mesurée après $26 \mathrm{~h}$ de stockage du lait à $5^{\circ} \mathrm{C}$.

\section{a)1. Périodes de sous-alimentation}

Sтоввs et al. [239] observent une lipolyse accrue chez des vaches faibles productrices $(6 \mathrm{~kg} / \mathrm{j})$ sous-alimentées fortement en fin de lactation (fig. 7). La même tendance est rapportée par JELlEMA et ScHIPPER [134] et AsTRup et al. [13] chez des vaches sous-alimentées modérément pendant 6 à 7 semaines en pleine lactation, et qui présentaient de fortes diminutions de production laitière. Par contre, ConNolly [60] enregistre une diminution de la lipolyse chez des vaches moyennes productrices $(13 \mathrm{~kg} / \mathrm{j}$ ) restreintes en fin de lactation (fig. 8).

Une sous-alimentation en début de lactation (75 à 80 p. 100 des besoins pendant 4 à 7 j) ne produit pas d'effet [39] ou tend à augmenter la lipolyse (fig. 9) de façon non systématique [13]. Avec une restriction plus poussée ( 50 p. 100 des besoins pendant 8 semaines), GHoLson et al. [105] n'enregistrent pas de variation de la lipolyse spontanée mais la lipolyse induite augmente.

Alors que Luthala et ANTila [165] n'observent pas d'effet du niveau des apports sur l'activité lipasique du lait, Borges [34] rap- 


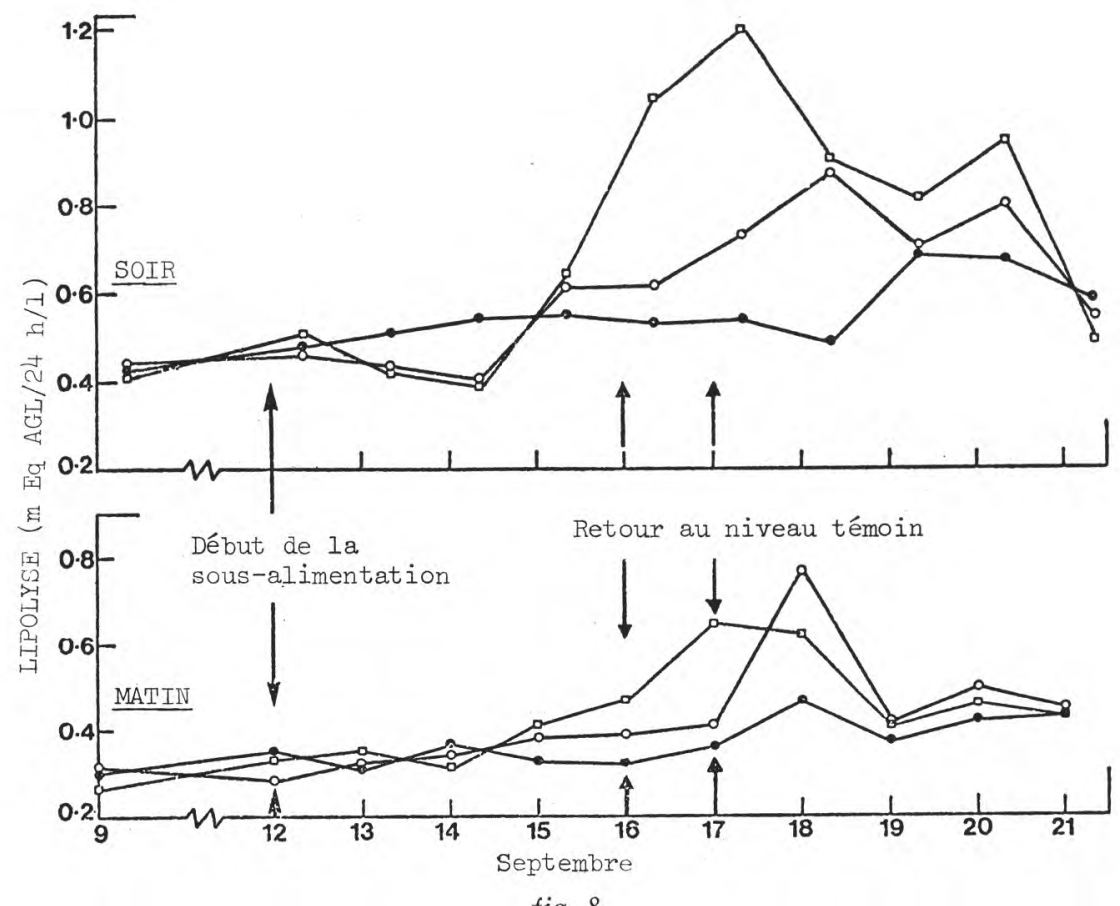

fig. 8

Influence de la sous-alimentation au pâturage sur la lipolyse spontanée du lait de vache en fin de lactation (d'après ConNolly, 1978 [60]).

- = Douze vaches témoins $(0,8 \mathrm{ha} /$ vache $)$.

$\square, O=$ Douze vaches restreintes à 0,1 ha/vache du 12 au 16 () ou au $17(0)$ septembre.

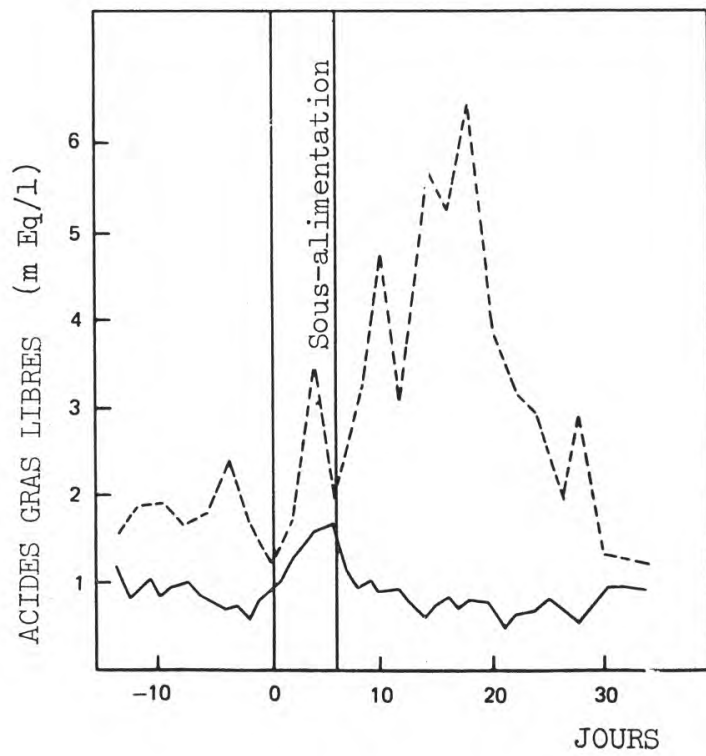

fig. 9

Teneur en acides gras libres dans le sang $(\longrightarrow)$ et dans le lait stocké $48 \mathrm{~h}$ à $\left.4^{\circ} \mathrm{C}(-.-)^{-}\right)$chez huit vaches en début de lactation (d'après Astrup et al., 1980 a [13]). Le jour 0 correspond au $25^{\mathrm{e}} \mathrm{j}$ de lactation environ. 
porte une diminution de celle-ci lors d'une sous-alimentation modérée (80 p. 100 des besoins).

La sous-alimentation des animaux produit donc des résultats variables. Une augmentation de la lipolyse spontanée semble se rencontrer surtout chez les animaux dont la production laitière est faible et/ou diminue fortement pendant la période expérimentale. L'augmentation de la susceptibilité du lait rapportée par GHoLsoN et al. [105], parallèlement aux faibles variations de l'activité lipasique, suggère que d'autres constituants du lait puissent être modifiés (globules gras,...). Par contre, il est possible que des diminutions d'activité lipasique [34] puissent intervenir dans les diminutions de lipolyse rapportées par CONNOLLY [60]. Ces modifications pourraient refléter des altérations du fonctionnement mammaire chez l'animal sous-alimenté qui réduit sa production laitière.

\section{a)2. Périodes de réalimentation}

Le passage des animaux d'une période de sous-alimentation à une période de réalimentation peut s'accompagner d'un accroissement important de la lipolyse pendant 2 à $4 \mathrm{j}$ (fig. 8) ou 2 semaines (fig. 9). Toutefois SтоввS et al. [239] ont, au contraire, observé une diminution $10 \mathrm{j}$ après la supplémentation (fig. 7).

Les expériences de ConNolly [60] effectuées dans des conditions " de terrain " et sur un grand nombre d'animaux suggèrent que ceux-ci soient en fait surtout sensibles aux stress alimentaires (changements de régime,...). Des variations dans le pouvoir activateur du sérum sanguin des animaux sur la lipolyse " in vitro » pourraient intervenir bien que ce type de données soit difficile à interpréter en relation avec la physiologie de la sécrétion lactée " in vivo ".

Quoi qu'il en soit les phénomènes en cause semblent être très complexes. Ainsi la succession sous-alimentation-réalimentation peut aussi bien se traduire par une augmentation continue (fig. 9), par une diminution suivie d'une augmentation (fig. 8) que par une augmentation suivie d'une diminution (fig. 7) de la lipolyse spontanée!

b) Composition de la ration

\section{b)1. Fourrages verts ou conservés}

De nombreuses études ont été consacrées depuis 1930 à la comparaison des effets sur la lipolyse de régimes à base de fourrages verts ou de fourrages conservés (foin, ensilages). Dans certains cas, les fourrages conservés semblent augmenter la lipolyse spontanée, mais cet effet résulterait en fait d'une sous-alimentation des animaux en raison de la mauvaise qualité des fourrages étudiés (revues $[132,133]$ ). Les différents régimes ne modifient en outre pas l'activité lipasique (ibid).

Les influences combinées du type de fourrage, du niveau alimentaire et du stade de lactation pourraient expliquer en partie les 
variations saisonnières de la lipolyse observées par ailleurs (voir par exemple, $[155,153])$.

\section{b)2. Rapport fourrages/concentrés}

Le rapport fourrages concentrés n'a apparemment pas d'influence sur la lipolyse spontanée [15], les AGL initiaux et l'activité LPL [217]. Celle-ci n'est d'ailleurs pas modifiée par des infusions de glucose [205].

\section{b)3. Taux de protéines}

Avec des régimes protéiprives ou déficients en protéines, l'activité tributyrinasique ou lipasique n'est pas modifiée [125, 204]. RANDOLPH et al. [204] n'observent pas d'effet d'une réduction des apports ( 80 p. 100 des besoins) sur la lipolyse. Par contre, SALIH et ANDERSON [217] constatent une augmentation des AGL initiaux et de la capacité du plasma sanguin à activer la LPL du lait avec un régime contenant 9 p. 100 au lieu de 18 p. 100 de matières azotées, bien que les teneurs en LPL et en sérumalbumine du lait tendent à diminuer légèrement.

\section{b)4. Lipides alimentaires}

L'addition de lipides au régime des vaches laitières se traduit généralement, comme chez les espèces monogastriques, par une augmentation du pouvoir activateur des sérums sanguins sur la lipolyse $[132,133$ ] et l'activité LPL [243] in vitro, probablement du fait de l'élévation des taux de lipoprotéines circulantes (ou des polypeptides activateurs qu'elles véhiculent) (fig. 10).

Ces données sont toutefois difficiles à relier à la lipolyse du lait car celle-ci n'a pas été mesurée systématiquement dans ces expériences, et les auteurs ne précisent pas toujours la nature, la quantité et la forme de présentation des lipides offerts aux animaux.

\section{b)4.1. Acides gras saturés}

La nature des acides gras alimentaires semble en effet jouer un rôle propre sur la lipolyse. Ainsi, Astrup et al. [16] observent une lipolyse accrue en ajoutant de l'acide palmitique (et dans une moindre mesure, myristique) au régime, contrairement à ce qui est observé avec l'acide stéarique ou de la farine de soja qui ne font pas varier la lipolyse. L'addition d'acide palmitique s'accompagne d'une élévation des taux de cholestérol et de phospholipides dans le sang (idonc probablement de certaines lipoprotéines circulantes), et du pouvoir activateur du sérum sur la lipolyse in vitro. En outre, elle se traduit par un enrichissement important de la matière grasse du lait en acide palmitique, alors qu'avec la distribution d'acide stéarique c'est essentiellement l'acide oléique qui est accru.

\section{b) 4.2. Huiles végétales protégées}

Des huiles végétales riches en acides gras insaturés, protégées contre les fermentations ruminales, tendent à diminuer la lipolyse 




fig. 10

Influence de la teneur du sang en lipoprotéines sur sa capacité à activer la lipoprotéine-lipase du lait (d'après SALIH et ANDERSON, 1979 a [217].

Six vaches recevant des quantités variables de lipides protégés dans le régime. Les capacités du plasma sanguin à activer la LPL du lait (fig. 10) et la lipolyse spontanée du lait (non figurée) sont étroitement liées dans cette expérience.

[15], ou à limiter son augmentation chez des vaches sous-alimentées [13]. Dans ce cas, la matière grasse du lait est enrichie en acides oléique et linoléique, et appauvrie en acides palmitique et myristique.

\section{b) 4.3. Discussion}

La nature et la forme de présentation des acides gras alimentaires semblent influencer de façon non négligeable le développement de la lipolyse dans le lait. Les acides gras saturés à chaîne moyenne (acide palmitique essentiellement) tendent à l'augmenter, alors que les acides gras longs insaturés (oléique et linoléique) ont l'effet inverse (mais dans ce cas des problèmes d'oxydation de la matière grasse peuvent se poser (voir par exemple [15]).

Ceci est à rapprocher des observations sur les faibles niveaux de lipolyse dans le lait d'animaux ingérant de l'herbe jeune au pâturage $[132,133,14]$. En effet, cette herbe est riche en lipides insaturés, et le lait est alors appauvri en acide palmitique et enrichi en acides gras à 18 atomes de carbone [154, 62].

Les mécanismes impliqués dans ces effets des acides gras sont inconnus. Plusieurs hypothèses ont été avancées : 
- une modification des propriétés de la matière grasse du lait, en particulier de la structure des triglycérides, de leur point de fusion ou de leur cristallisation (cf. $\S$ III $A_{2}$ ). Toutefois, des niveaux faibles de lipolyse ont parfois été enregistrés dans des laits relativement riches en acide palmitique [16]. Par ailleurs, l'enrichissement du lait en acide linoléique après distribution de lipides protégés ne semble pas modifier l'ultrastructure des globules gras ou de leurs membranes [235];

- une liaison entre le pouvoir activateur du sérum sanguin sur la lipolyse in vitro, et la lipolyse in vivo. Cette hypothèse ne peut pas être retenue puisque les variations de ces 2 paramètres ne sont pas corrélées [133], et même opposées dans le cas des lipides insaturés protégés;

- des modifications du métabolisme lipidique hépatique et/ou mammaire, conduisant soit à une sécrétion différente de LPL [13] soit à une altération du passage d'activateurs sanguins dans le lait (Astrup, 1979, communication personnelle). Il n'existe toutefois pas d'arguments expérimentaux en faveur de ces hypothèses. L'activité lipasique du lait semble quant à elle peu sensible à la supplémentation en lipides [165].

\section{$4^{\circ}$ INFLUENCE DES MAMMITES}

Les AGL initiaux $[249,218]$ et la lipolyse spontanée $[245,203$, $67,17]$ sont plus élevés dans les laits mammiteux que dans les laits normaux. Cette relation n'a toutefois pas été vérifiée dans d'autres études, probablement en raison des grandes variations individuelles enregistrées [132, 133].

Dans les laits mammiteux, les différents composants du système lipolytique peuvent être affectés de façon à augmenter la lipolyse :

- les globules gras contiennent moins de matériel membranaire et celui-ci est appauvri en protéines (protéolyse probable) et en phospholipides (1) avec une diminution de la teneur en acides gras longs saturés $[203,91,4]$. Il en résulte une susceptibilité accrue de la matière grasse à la lipolyse [218] ;

- l'activité de la lipase varie peu $[245,232]$. Sa distribution est toutefois modifiée en faveur du sérum [218] probablement par suite d'une augmentation de la force ionique $[162,147]$ ou d'une protéolyse des caséines [7] (2), qui peuvent se produire dans ce type de laits. De plus, l'affinité de la lipase pour son substrat tend à augmenter

(1) Fitz-Gerald et al. [96] rapportent une activité phospholipasique accrue dans les laits provenant de quartiers infusés avec des endotoxines.

(2) Les caséines solubles augmentent dans les laits mammiteux [voir par exemple $78,228,3]$. 
[160], ainsi que le $\mathrm{pH}$ du lait et la proportion de lipase liée à la crème [17].

D'autres auteurs [196, 165, 67] ont rapporté une baisse d'activité lipasique dans les laits mammiteux, mais ces observations s'expliquent probablement par l'activité protéolytique qui s'y développe [218] :

- des protéines d'origine sanguine passent en quantité accrue dans les laits mammiteux $[180,147]$. Toutefois, SALIH et ANDERson [218] n'ont pas pu montrer la présence d'activateurs de la lipolyse dans ces laits. Ceux-ci sont aussi enrichis en arylestérase d'origine sanguine (revue [147]), mais cette enzyme ne semble pas intervenir dans la lipolyse du lait [75];

- le nombre de cellules somatiques augmente, et avec celles-ci l'activité protéolytique (cf. ci-dessus) et lipolytique (cf. § III A 7) du lait ;

Ces changements susceptibles de conduire à une augmentation de la lipolyse peuvent toutefois être tempérés par d'autres modifications ayant un effet inverse :

- l'enrichissement du lait en protéines non spécifiques et en minéraux peut conduire à une inhibition de l'activité LPL (cf. § II C 2-3) et de la lipolyse [218];

- l'enrichissement éventuel du lait en leucocytes ou en fragments de cellules mammaires pourrait conduire à une activité lipogénique accrue, expliquant des diminutions des teneurs en AGL de laits mammiteux après la traite $[167,218]$.

\section{$5^{\circ}$ CONCLUSION}

La multiplicité des facteurs de variation, l'hétérogénéité des réponses d'une expérience à l'autre, le manque de données sur l'évolution des différents composants du système lipolytique et leurs relations avec la physiologie de l'animal en lactation rendent difficile une bonne compréhension des variations de la lipolyse spontanée.

L'examen de celles-ci chez d'autres espèces pourrait permettre d'en améliorer la compréhension. En effet, outre l'intérêt intrinsèque qui se rattache à celles-ci, une telle étude comparative devrait faciliter la mise en évidence de certains mécanismes ou conduire à des hypothèses donnant lieu à des investigations ultérieures. 